of managing your own personal and employment history to become an effective leader. As stated by the authors, "it is an unfortunate aspect of the librarian profession that it is sometimes difficult for individuals to let past issues go by the wayside... [T] here often seems to be a tendency to remember into perpetuity decisions and mistakes one made in the past and refuse to acknowledge that leaders grow, develop, and improve their skills over time." Despite this rather pessimistic statement, the chapter provides many tips and techniques for developing and building a successful leadership style, both for those new to the organization and for those individuals moving up to a managerial role within the same organization.

Chapter 8, "Evaluating the Change and Yourself as a Change Leader," addresses both the importance of assessment and the reasons assessment is generally avoided at the completion of a project. The authors remind the reader that, whatever broad assessment data are gathered, the data must answer four basic questions to fully assess the change leadership: How did I do as a leader for this change initiative? What did I do well? What did I do poorly? What can I do to improve for next time? These questions reinforce the concept that assessment not only serves to measure the degree of success of the particular project but also to ensure that the change leader improves with each project.

In the concluding Chapter 9, "ChangeSpecific Challenges," the authors focus on those changes, such as complex large-scale space or vision changes, that bring special challenges to the process. In each example,

\section{Index to advertisers}

$\begin{array}{lr}\text { AAAS/Science Online } & \text { cover } 3 \\ \text { ACRL Publications } & 10 \\ \text { Annual Reviews } & 5 \\ \text { CHOICE Reviews Online } & 6 \\ \text { Counting Opinions } & \text { cover } 2 \\ \text { Digital Libr. Sys. Grp. } & \text { cover } 4,7,9 \\ \text { EBSCO } & 2 \\ \text { John Wiley } & 1\end{array}$

the authors note and provide guidance on how to address the management challenges in these unique situations.

This review began with the provocative statement that The Challenge of Library Management: Leading with Emotional Engagement should be required reading in every library and information science graduate program. The authors emphasize that the library profession needs proactive engaged individuals who exhibit initiative, collaborate with others, take responsibility for their own professional development, and are committed to high-quality performance standards. Just as managers and administrators must effectively initiate, manage, and implement change (despite being hampered or frustrated by the library context), individuals entering the profession must be willing to be the employee the library needs now and as the future unfolds.-Catherine A. Lemmer, Indiana University Robert $H$. McKinney School of Law.

John J. Huber. Lean Library Management: Eleven Strategies for Reducing Costs and Improving Customer Services. New York: Neal-Schuman Publishers, Inc., 2011. 197p. alk. paper, $\$ 75.00$ (ISBN 9781555707323). LC2010-050755.

John Huber has a unique perspective on how to help library systems improve customer satisfaction while reducing costs. He has taken the concepts of Lean Manufacturing typically used in business and industry and has applied them to the library environment. In Lean Library Management, Huber explains that Lean is a different way to think about organizing library processes. Huber makes a strong case that, if library leaders were to apply Lean strategies as recommended, customer service could indeed improve while reducing costs.

In the Prologue, Huber explains what Lean is and background information about this concept. He gives a clear and basic description of Lean, while respecting that his audience is not likely to know much about Lean Manufacturing. In the 
Afterword, he has included helpful descriptions of some Lean tools, along with some examples of how to use these tools in a library context. These descriptions are particularly informative; the book would have been better served had they had been more prominent in the book.

Sandwiched between the Prologue and Afterword, there are a series of eleven strategies that library employees can apply to improve customer service and reduce costs. The first four strategies provide the building blocks of Lean strategies. The first strategy explains that librarians need to think of libraries as businesses, focusing on service improvements and reduced costs just as businesses do. The second strategy focuses on the difficulty that library staff may have with implementing change and provides some strategies to help libraries embrace change. The third strategy explains that every library has delivery service chains, which are systemwide processes that cross departmental boundaries. Any change should take into account the process as a whole, not individual segments of a process. Finally, the fourth strategy involves developing useful and meaningful performance metrics to ensure that library leaders are making appropriate inferences about services and costs.

Strategies 5 and 6 offer specific examples of applying Lean tools to the library environment. The fifth strategy examines the new book process, and the sixth looks at customer holds and reserves. Huber explains that both new books and holds/ reserves are examples of service delivery chains and walks the reader through using Lean tools to improve the efficiency of these service delivery chains.

The seventh strategy recommends that library leaders need to align budgets with delivery service chains, and strategy 8 discusses new ways to measure and collect circulation statistics. The ninth strategy discusses how to apply Lean tools to electronic resource usage, while the tenth strategy suggests how to facilitate effective resource ordering to meet the needs of the user more quickly. The eleventh strategy recommends implementing Lean processes when an institution is building a new facility.

One strength of this book is the perspective of the author. As a consultant with an engineering background, Huber has a solid expertise in Lean Manufacturing. Huber does not have a library background; however, he seems to have a sincere interest in the well-being of library systems. This background in Lean Manufacturing, married with his unique experiences with libraries, has given Huber a niche expertise in suggestion of application of Lean tools to library systems. As an outsider to the library world, he has not been trained to do things a certain way; he seems to have a fresh perspective and is not embedded in static systems that do things the way they have always been done. Although his background is in Lean Manufacturing, Huber has successfully written a book for librarians, using language and concepts specific to the field of librarianship. Moreover, Huber's writing style is conversational and down-to-earth. He has woven personal stories, illustrations, and anecdotes throughout this book. His storytelling makes his ideas relatable, and his metaphors are interesting. He could have been more concise, however; readers do not always have to digest extended conversations or decipher metaphors to get to the point-just get to the point.

At the end of each section, Huber has written a paragraph of review. Unfortunately, the reviews did not always directly and concisely summarize the content of the section. That is to say, the reviews cannot be relied upon to recap accurately the essence of the section. Further, the relationship among the various strategies was not always clear. For example, strategies 1 through 4 seem to be about creating an environment conducive for Lean implementation, though that is not apparent from the review. Other strategies were specific case examples of Lean applications. Also, Huber might have elaborated 
upon how his strategies and recommendations might be different for different types of library systems. For example, the goals, missions, and user groups are different for a public library than they are for an academic library. Still, some of Huber's ideas are very controversial and thought provoking. Strategy 10, for instance, discusses alternatives to traditional selectors for collection development. Regardless of whether a reader embraces all of the ideas Huber presents, I think his book will motivate readers to challenge the way they do things in their libraries.

Huber points out that, for a library system to implement Lean strategies, the library must embrace Lean concepts from both the top down and bottom up. Therefore, a diversity of library employees from across the workplace hierarchy would benefit from reading this book. Primarily, however, I think this book would be of interest to senior library employees in decision-making positions. If a library system is undergoing change to become Lean, I would recommend that staff in that library system read this book as well to help explain to staff what changes are expected and to elicit bottom-up input to augment the change process. - Nicole Nolan, The University of Western Ontario.

\section{William S. Peterson and Sylvia Holton}

Peterson. The Kelmscott Chaucer: A Census. New Castle, Del.: Oak Knoll Press, 2011. 272p. alk. paper, $\$ 95.00$ (ISBN 9781584562894). LC2011-003557.

For nearly three decades, Prof. William Peterson has been one of our best and surest guides to William Morris and his Kelmscott Press. Now he has partnered with his wife, Sylvia Holton Peterson, to give us the "other" project they had quietly been working on while doing research for earlier monographs, a census of known extant copies of the Kelmscott Chaucer (KC). And what a census this is! If you have any doubts about the iconic status of William Morris's chef d'oeuvre, this extraordinary volume will put them all to rest. With this book, Morris's Chaucer joins the ranks of the Gutenberg Bible and Shakespeare's First Folio as deserving of a census all its own. But no mere census this. Rather, this dense, detailed, elaborate, and altogether remarkable achievement is nothing less than a fundamental contribution to very late 19th- and 20th century book history. Scholars as well as librarians and curators will want to make its acquaintance. The Petersons have at last shared with us all of their notecards, diaries, databases, and spreadsheets spanning more than thirty years of labor. This book is a fitting capstone to a long and productive career.

First, the taxonomy. The core of the census comprises two meaty chapters: one devoted to the vellum copies of the $\mathrm{KC}$, the other to the paper, and both according to the same layout. The latter consists of: present location; binding notes; detailed provenance notes; biographical capsules of principal owners along the way; and side notes with full bibliographic information. Photos of many of the collectors are a welcome bonus. In addition, there is a remarkable trove of supplementary detail, arrayed over three chapters: unlocated copies; a seemingly exhaustive listing of all dealer and auction catalogues in which the $\mathrm{KC}$ has appeared over the years; and an alphabetical listing of all known binders who have contributed to the $\mathrm{KC}$, together with substantial background and bibliographic notes. Finally, three appendices share with us some of the most useful source material that undergirds the census: the sales ledger of Bernard Quaritch recording the more than one hundred copies of the KC sold before publication; the mailing list for the Kelmscott Press (now in the Morgan Library); and a detailed listing of the more useful pieces of correspondence from Sydney Cockerell to various collectors of the KC in the early 20th century (much of which is at the Grolier Club and has been edited and published). In short, all one might ever want to know about the fortunes of the $\mathrm{KC}$, and more, is here.

This dry summary, however, does not begin to do justice to the richness of this 